\title{
EFFECTIVENESS OF VISION SCREENING TRAINING MODULE IN IMPROVING THE LEVEL OF KNOWLEDGE ON VISION SCREENING AMONG PRE-SCHOOL TEACHERS IN KLANG VALLEY MALAYSIA
}

\author{
Omar $\mathbf{R}^{1,2}$, Knight $V F^{3}$, Tan $X L^{1}$, Ahmad Zahidi $A A^{1}$, and Mohd Saat $\mathrm{NZ}^{4}$ \\ ${ }^{1}$ Optometry and Vision Sciences Program, Faculty of Health Sciences, Universiti Kebangsaan Malaysia, Kuala Lumpur, \\ Malaysia \\ ${ }^{2}$ University Community Transformation Centre, Universiti Kebangsaan Malaysia, Selangor, Malaysia \\ ${ }^{3}$ Faculty of Medicine and Defence Health, National Defence University of Malaysia, Kuala Lumpur, Malaysia \\ ${ }^{4}$ Biomedical Sciences Program, Community Health Centre, Faculty of Health Sciences, Universiti Kebangsaan Malaysia, \\ Kuala Lumpur, Malaysia
}

\section{Correspondence:}

Professor Datuk Dr Rokiah Hj Omar

Optometry and Vision Sciences Programme,

Faculty of Health Sciences,

Universiti Kebangsaan Malaysia,

Jalan Raja Muda Abdul Aziz,

50300 Kuala Lumpur, Malaysia

Phone number (office): +603 92895085

Email:r_omar@ukm.edu.my

\begin{abstract}
Empowering lay screeners, such as pre-school teachers, on vision screening is a cost-effective way to ensure larger populations of children can be screened. Although the validity of lay screeners in conducting vision screening were reported in several studies, none showed data concerning improvement of the level of knowledge among lay screeners after completing vision screening training, which could indicate the effectiveness of the training program. This study aimed to determine the level of knowledge of pre-school teachers before and after attending a training program. Sixty pre-school teachers from Tabika and Taska KEMAS were randomly selected. The Study Group $(n=30)$ was given theory and practical training on vision screening, whereas the Control Group $(n=30)$ was only given brief verbal instructions on how to conduct the screening. A theory test containing 15 questions related to the training modules were administered to both groups, before and after their training/briefing respectively. The findings showed that the level of knowledge among preschool teachers in the Study Group (73.24 $\pm 11.73 \%$ ) was significantly higher than the Control Group (56.22 $\pm 13.11 \%)(p<0.01)$. There was also a significant improvement in the level of knowledge among pre-school teachers in the Study Group after the training $(p<0.001)$, whereas no improvement was noted among preschool teachers in the Control Group $(p=0.636)$. This study shows the importance of conducting training for pre-school teachers prior to their involvement in conducting vision screening in order to deliver an effective vision screening program to the preschoolers.
\end{abstract}

Keywords: preschoolers, vision screening training, teachers, level of knowledge, theory test

\section{Introduction}

Malaysia as a developing nation, 7 out of 100 children are reported to suffer from vision impairment, in which uncorrected refractive error $(5.8 \%)$ is seen as being one of the main causes, followed by amblyopia (1.3\%), strabismus $(1.0 \%)$ and ocular anomalies (0.8\%) (1). As previously reported by Kong et al. (2), $7 \%$ to $31 \%$ of childhood blindness and visual impairment is avoidable, $10 \%$ to
$58 \%$ is treatable, and $3 \%$ to $28 \%$ is preventable among populations in developing countries. This suggests the need for a nationwide, large scale vision screening program that should be conducted on a regular basis to ensure good visual prognosis for children with vision impairment through early detection and prompt treatment.

In Malaysia, vision screening is presently conducted by trained school nurses within the School Health Team 
Program under the Ministry of Health Malaysia for children aged 7 to 12 years. The program has been recently expanded to include pre-school children aged 6 years, in line with the establishment of pre-school programs in a certain number of primary schools across the nation. However, only those who attend public schools enjoy this privilege, whereas children who study in private pre-schools, private primary schools or those children aged less than 6 years may not be screened actively. This may result in late detection of potential vision impairment. Since the visual prognosis for vision impairment among children, such as in cases of amblyopia is better when treated early, there is a need to have a nationwide vision screening program easily accessible to children. However, due to limited school health work force, where the numbers of optometrists and school nurses are small and limited to only public education programs, a broader and more equitable means of performing universal vision screening is needed. Within the current system in place, cost is a major factor, and the provision of eye care or medical professionals to conduct universal vision screening for school children would require larger numbers of these professionals to be placed within the program thus increasing the emolument cost of public healthcare services or reduction of other public vision care services to enable these personnel to be transferred to the school health program.

There are several vision screening training programs available for lay screeners. The effectiveness of trained school teachers in conducting vision screenings has been reported, in which they were shown to be competent in conducting effective vision screening for children (3-6). Therefore, it may be more cost effective to empower school teachers to conduct the vision screening program so that more schools can implement it without having to wait for the availability of a public school health program. The delivery of vision screening services by trained school teachers would present a cost-effective solution towards universal vision screening. It would reduce dependency on limited existing resources. This will allow larger numbers of children to be screened through a larger population of screeners than currently available and decrease disruption in teaching and learning activities in each school.

According to the American Optometric Association (2019), limited testing, inadequate testing equipment and untrained personnel are among the limitations in implementing vision screening programs (7). There have been studies reporting the skill effectiveness of trained lay screeners in conducting vision screening of children. However, the level of knowledge of these screeners to competently assess and interpret the screening results was not studied in detail. Juggernath \& Knight reported that a vision screening training program involving primary school teachers increased their knowledge on implementing vision screening tests, and this has led to improved vision screening results of the children assessed by these trained teachers (8). It has been shown that trained school teachers can yield high true negative rates and reasonably good true positive rates for vision screening of children
(6). However, there is no study on the gain in level of knowledge among teachers regarding vision screening after a training program. A lack of knowledge would result in the personnel having low confidence in providing specific recommendations to patients (9). The competency of screeners has been shown to improve when specific training interventions were conducted (10). Considering all the above factors, we have developed a vision screening training program for pre-school teachers (11). The aim of this study was to assess the effectiveness of this locally designed vision screening training module in improving the level of knowledge on vision screening among pre-school teachers in the Klang Valley, Malaysia. In addition, we also evaluated the relationship between age and working experience with the level of knowledge of these pre-school teachers. This would potentially have a positive impact on the effectiveness of the vision screening training program currently implemented at the national level.

\section{Materials and Methods}

\section{Research population and data collection}

This was a prospective study, which targeted pre-school teachers in Klang Valley, Malaysia. The study population included pre-school teachers from Tabika's and Taska's under the management of the Department of Community Development (KEMAS), Ministry of Rural and Regional Development. Inclusion criteria for subjects in this study were a) pre-school teachers employed by KEMAS; b) hold academic qualifications of at least SPM certificate (secondary school level); c) have at least two years working experience with children.

The sample size $(n)$ required for this study was calculated using the Snedecor \& Cochran (12) formula, on comparisons between two independent means, as follows:

$\mathrm{n} 1=\mathrm{n} 2=2 \mathrm{~K} \sigma^{2} / \Delta^{2}$

The standard deviation of VA measurement $(0.135$ LogMAR) for the sample size calculation was obtained from a previous study, i.e. The Vision in Preschoolers (VIP) Study Group (13). The sample size in this study was calculated based on detection of a difference of 0.1 LogMAR between the Study Group and Control Group with 80\% power, 95\% confidence interval and a significance $(\alpha)$ of 0.05 . The number of subjects required in this study was calculated to be 28 for each group. However, the sample size for both the Study Group and the Control Group was set at 30 individuals per group after considering a $10 \%$ of dropout rate. Lists of names of suitable and eligible TABIKA and TASKA KEMAS teachers were obtained from the KEMAS state headquarters of both the Federal Territory of Kuala Lumpur and Selangor. This study therefore involved 60 pre-school teachers randomly selected using a random number table and then randomly divided to two groups, i.e. the Study Group ( $n=30)$ and Control Group $(n=30)$. This study followed the Helsinki Declaration for Human Subjects and ethical approval was obtained from the Universiti Kebangsaan Malaysia Research and Medical 
Ethics Research Committee, (Ethics approval code UKM1.5.3.5/244/SPP/NN0242010) and was also approved by the Federal Territory and Selangor State KEMAS offices. The selected pre-school teachers were then briefed about the study and written informed consent was obtained from all participants.

\section{Vision Screening Training Program}

This study was divided into two stages. The first stage was the development of a pre-school vision screening module for pre-school teachers. The second stage was determination of the level of knowledge on preschool vision screening by pre-school teachers in both groups before and after receiving training or a briefing, respectively. In the Study Group, teachers underwent comprehensive training on pre-school vision screening which included theoretical and practical sessions using the KieVision Pre-school Vision Screening $\mathrm{Kit}^{\mathrm{TM}}$. On the other hand, the Control Group was only given a descriptive briefing on the use of KieVision Pre-school Vision Screening $\mathrm{Kit}^{\mathrm{TM}}$ in conducting vision screening.

\section{Stage 1: Development of the vision screening module for pre-school teachers}

The vision screening module for pre-school children, aged 4 to 6 years, was based on a vision screening model for pre-school children described by Duratul Ain (14). This Pre-school Vision Screening Module consisted of three parts: 1) Vision Screening for Pre-school Children Manual; 2) Vision Screening Kit 3) Vision Screening Teaching Module for Pre-school Teachers. The Pre-school Vision Screening Manual is divided into three sections. The first section describes the definition of vision screening and its significance. The second section describes the equipment used in the KieVision Pre-school Vision Screening Kit ${ }^{\mathrm{TM}}$ as well as how to store and care for the equipment. The third section describes the pre-school vision screening tests that need to be done, the steps needed to conduct the screening and the method of recording the screening tests results. The vision screening tests to be performed included external eye observation, visual acuity test (VA) and Hirschberg's test.

The Pre-school Vision Screening Module designed by the research team was then refined in an expert panel workshop before being finalised. The panel members consist of three optometry experts from the Optometry and Vision Sciences Programme, Community Health Centre, Faculty of Health Sciences, Universiti Kebangsaan Malaysia (UKM), two education experts from the Faculty of Education, UKM, three optometrists in private practice and a private pre-school teacher. The panel members were given a set of the pre-school vision screen module documents a week prior and were then asked to provide comments and feedback about the module. Their comments and feedback were discussed during the workshop. Improvements were then made to the module based on the comments and suggestions given by these experts.
A validation process was then carried out after the refinement of the Pre-school Vision Screening Module. A KieVision Pre-school Vision Screening $\mathrm{Kit}^{\mathrm{TM}}$ and the Preschool Vision Screening Module for children aged 4 to 6 years was then given to two private preschool teachers and two KEMAS preschool teachers. These teachers were given theoretical and practical training on the screening tests as described in the module. They were then instructed to conduct screening tests on 30 pre-school children aged 4 to 6 years in their respective preschools. After they have completed the screening, the same children were seen by optometrists who repeated the screening tests on the same children using the same screening module and recording form. The screening tests results by both the preschool teachers in the study group and optometrists were found to correlate very well $(\mathrm{AC} 1 \geq 0.89)$ [15]. The vision screening conducted by teachers in the study group was also regarded as a valid test as indicated by a high sensitivity and specificity values (sensitivity $=79 \%$, specificity $=95 \%$ ).

\section{Stage 2: Determination of the level of knowledge of pre-school teachers in both groups of pre- school vision screening before and after receiving training/briefing}

In order to determine the level of knowledge of pre-school teachers about the screening tests, all the teachers involved in this study were required to sit for a written theory test. This test was carried out before any training or briefing on the pre-school vision screening was conducted. Questions were based on the module. The language used was Bahasa Malaysia. The questionnaire was reviewed by the expert panel members during the expert panel workshop.

The theory test consists of 15 multiple choice questions as shown in Table 1. Each question contains five statements in which the pre-school teachers were required to decide whether the statement was true or false. One mark is given for every correct answer and no mark is given nor deducted for every incorrect answer. Thus, a maximum of five marks and a minimum of zero mark will be obtained for each question. A total of 75 marks would be the maximum for this theory exam and the marks are prorated into $100 \%$ scoring. The questions are separated into two categories. The first category (Q1 to Q6) tests on preparation to conduct the pre-school vision screening tests. Questions in this category test the teacher's knowledge on the definition of vision screening and its significance towards detection of vision impairments (Q1 and Q2). In addition, the types of tests used in pre-school vision screening and the equipment used were also questioned (Q3 to Q6). The second category (Q7 to Q15) examines the knowledge of teachers about the conduct of the screening tests. These include questions on the procedures and normal values of each test used in the vision screening (Q7 to Q14). Question 15 examines the referral method if a child needs to be referred for further eye examination. The teachers were asked to answer the questions using an Optical Mark Recognition (OMR) form provided to them. The test duration was 30 minutes and it was conducted in a lecture 
room at the Optometry and Visual Science Program, Faculty of Health Sciences, UKM.

Table 1: Overview of the questions contained in the theory test

\begin{tabular}{ll}
\hline No. & $\begin{array}{l}\text { Question } \\
\text { Soalan }\end{array}$ \\
\hline Q1 & $\begin{array}{l}\text { What is vision screening test? } \\
\text { Apakah ujian saringan penglihatan? }\end{array}$ \\
Q2 $\quad \begin{array}{l}\text { Impact of undetected vision impairments } \\
\text { Kesan daripada gangguan penglihatan yang } \\
\text { tidak dikesan }\end{array}$ \\
Q3 $\quad \begin{array}{l}\text { Tests included in pre-school vision screening } \\
\text { Ujian yang terlibat dalam saringan penglihatan }\end{array}$ \\
Q4 $\quad \begin{array}{l}\text { Equipment used for pre-school vision screening } \\
\text { Peralatan yang digunakan dalam saringan } \\
\text { penglihatan } \\
\text { Method to take care of screening equipment } \\
\text { Kaedah penjagaan alat saringan penglihatan }\end{array}$ \\
Q6 $\begin{array}{l}\text { Record book for vision screening tests } \\
\text { Buku rekod untuk ujian saringan penglihatan }\end{array}$ \\
\hline
\end{tabular}

\section{No. Question}

Soalan

Q7 External observation

Pemerhatian Luaran

Q8 Normal eye/

Mata norma

Q9 Hirschberg's Test

Ujian Hirschberg

Q10 Procedures on conducting Hirschberg's Test

Langkah-langkah mengendalikan ujian Hirschberg

Q11 Distance visual acuity (VA) test/ Ujian akuiti visual (VA) jauh

Q12 Normal value for distance VA Nilai normal VA jauh

Q13 Equipment used in VA test Peralatan yang digunakan dalam ujian VA

Q14 Procedures to conduct VA test Langkah-langkah untuk melakukan ujian VA

Q15 Referral of children who has failed the vision screening tests

Rujukan kanak-kanak yang gagal ujian saringan penglihatan
The teachers involved in this study were divided into two groups, the Study Group ( $n=30$ ) and the Control Group $(n=30)$. The teachers in the Study Group participated in a training course on how to conduct a vision screening program on pre-school children (the module developed for this study). The training course was divided into two parts, i.e. the first two hours consisted of the theoretical aspects of the screening program and the final two hours consisted of a practical session, where the subjects were introduced to and taught how to use the KieVision Pre-school Vision Screening $\mathrm{Kit}^{\mathrm{TM}}$. The training session was facilitated by four graduate optometrists assisted. Pre-school teachers in the Control Group on the other hand, were provided with a set of the same KieVision Pre-school Vision Screening Kit ${ }^{\mathrm{TM}}$ but did not receive any training nor provided with the manual of the pre-school vision screening program. The teachers in this group were only given a description of the equipment contained in the kit and were shown how they are used by an optometrist. They were also taught how to complete the screening record form.

After all the pre-school teachers in both Study and Control Groups had completed the practical session, they were asked to sit for a second written theory test. The questions contained in the test were the same set of questions used previously. The purpose of these tests was to determine the level of knowledge of these pre-school teachers in both the Study and Control groups before and after they had completed their training/briefing and practical sessions. Teachers were given the same test duration (30 minutes) to answer all the questions using the OMR answer sheet provided. Answer papers were then sent to the UKM computer center for processing and marking. The grading of theory test was divided into five categories based on their overall scores, ranging from excellent (80 - 100\%), good $(60-79 \%)$, fair $(40-59 \%)$, poor (20 - 39\%) to very poor (0 - 19\%).

\section{Data Analysis}

Descriptive analysis was conducted on the demographic details of the teachers, deriving mean, standard deviation, range and percentage of the theory test results. The correlation test was then conducted to determine the relationship of age and working experience on the level of knowledge of these pre-school teachers. The mean theory test results between pre-school teachers in the Study and Control Groups were compared using the Student-t test for normally distributed data or the Mann-Whitney test if the data was not normally distributed. The theory test results of the teachers before and after the training were compared using paired-t test for normally distributed data or Wilcoxon test for non-normally distributed data. 


\section{Results}

The 60 pre-school teachers enrolled as subjects in this study included 40 pre-school teachers from Tabika KEMAS and 20 pre-school teachers from Taska KEMAS. The age of pre-school teachers ranged from 23 years to 51 years with a mean age of $38.37 \pm 10.28$ years. The mean duration of teaching experience was $13.77 \pm 9.62$ years. The mean score of correct answers for each question is summarised in Table 2. The mean score for the questions in the first category (Q1 to Q6) was $3.61 \pm 0.36$ while the mean score for the questions in the second category (Q7 to Q15), was $3.12 \pm 0.50$. This indicated that the pre-school teachers had better knowledge on the preparations for pre-school vision screening compared to the conduct of pre-school vision screening tests. It was found that Q5 had the highest correct answer mean of $4.23 \pm 1.03$ while Q9 and Q12 had the lowest correct answer mean of $2.40 \pm 1.11$ and $2.45 \pm$ 1.56. This suggested that preschool teachers had a better understanding of the care of vision screening equipment and less understanding about the Hirschberg's Test as well as the normal values for distance Visual Acuity tests.

Table 2: Mean score of correct answer on theory test before the training or briefing

\begin{tabular}{lc}
\hline No. & $\begin{array}{c}\text { Mean Score } \pm \text { SD } \\
(\mathbf{n}=60)\end{array}$ \\
\hline Q1 & $3.65 \pm 1.01$ \\
Q2 & $3.33 \pm 1.20$ \\
Q3 & $3.37 \pm 1.19$ \\
Q4 & $3.32 \pm 0.93$ \\
Q5 & $4.23 \pm 1.03$ \\
Q6 & $3.77 \pm 1.03$ \\
\hline Q7 & $3.40 \pm 1.27$ \\
Q8 & $4.00 \pm 1.12$ \\
Q9 & $2.40 \pm 1.11$ \\
Q10 & $3.43 \pm 1.06$ \\
Q11 & $2.90 \pm 0.86$ \\
Q12 & $2.45 \pm 1.56$ \\
Q13 & $3.15 \pm 1.21$ \\
Q14 & $3.30 \pm 0.94$ \\
Q15 & $3.03 \pm 0.99$ \\
\hline
\end{tabular}

Within the Study Group, there was an increase in the mean score for all questions after the training was given. Preschool teachers from the Study Group managed to score more than 4 for all questions except Q2 ( $\min$ score $=3.77$ $\pm 1.04)$, Q7 ( $\min$ score $=3.53 \pm 1.33)$ and Q9 ( $\min$ score $=$ $3.93 \pm 1.11$ ). It was noted that Q11 was the question with the lowest score (mean score $=3.27 \pm 0.79$ ). The highest score was seen with Q8, which is a question that concerns with the definition of a normal eye (mean score $=4.47 \pm$
0.63). In the Control Group, there was not much difference between the score of each question either before or after they received the briefing. Only three of the questions displayed a mean score of more than 4, which were Q4 $(\mathrm{min}$ score $=4.13 \pm 1.17), \mathrm{Q} 5(\mathrm{~min}$ score $=4.40 \pm 0.89)$ and Q8 ( $\min$ score $=4.20 \pm 1.06)$. Q12 had a lowest mean score $(2.30 \pm 1.15)$.

Table 3 summarises the pre-school vision screening theory test results on knowledge for all 60 pre-school teachers according to performance category before and after the intervention. Before the training, analysis showed that majority of the pre-school teachers had poor (36.6\%) to fair knowledge (55.0\%) of pre-school vision screening. Overall, there were only 5 pre-school teachers who managed to obtain a good score (8.3\%) while none of the teachers obtained an excellent or very poor score. The pre-training theory test score ranged from $20 \%$ to $78.67 \%$. The mean score of the theory test results obtained at the beginning of the study for the Control Group was $57.47 \pm 9.67 \%$ and Study Group was $51.31 \pm 12.74 \%$ (Table 4). Teachers in the Control Group obtained a significantly higher score compared to those in the Study Group ( $p=0.039)$.

Table 3: Pre-school vision screening theory test results on knowledge for all pre-school teachers by category

\begin{tabular}{|c|c|c|c|}
\hline \multirow{2}{*}{$\begin{array}{l}\text { Knowledge } \\
\text { Scoring Category } \\
\text { Percentage (\%) }\end{array}$} & \multicolumn{3}{|c|}{ Before Training/Briefing } \\
\hline & $\begin{array}{l}\text { Study } \\
\text { Group } \\
(n=30)\end{array}$ & $\begin{array}{l}\text { Control } \\
\text { Group } \\
(n=30)\end{array}$ & $\begin{array}{l}\text { Total } \\
(n=60)\end{array}$ \\
\hline $\begin{array}{l}\text { Very poor } \\
(0-19 \%)\end{array}$ & $\begin{array}{c}0 \\
(0.0 \%)\end{array}$ & $\begin{array}{c}0 \\
(0.0 \%)\end{array}$ & $\begin{array}{c}0 \\
(0.0 \%)\end{array}$ \\
\hline $\begin{array}{l}\text { Poor } \\
(20-39 \%)\end{array}$ & $\begin{array}{c}14 \\
(46.7 \%)\end{array}$ & $\begin{array}{c}8 \\
(26.7 \%)\end{array}$ & $\begin{array}{c}22 \\
(36.7 \%)\end{array}$ \\
\hline $\begin{array}{l}\text { Fair } \\
(40-59 \%)\end{array}$ & $\begin{array}{c}16 \\
(53.3 \%)\end{array}$ & $\begin{array}{c}17 \\
(56.7 \%)\end{array}$ & $\begin{array}{c}33 \\
(55.0 \%)\end{array}$ \\
\hline $\begin{array}{l}\text { Good } \\
(60-79 \%)\end{array}$ & $\begin{array}{c}0 \\
(0.0 \%)\end{array}$ & $\begin{array}{c}5 \\
(16.6 \%)\end{array}$ & $\begin{array}{c}5 \\
(8.3 \%)\end{array}$ \\
\hline $\begin{array}{l}\text { Excellent } \\
(80-100 \%)\end{array}$ & $\begin{array}{c}0 \\
(0.0 \%)\end{array}$ & $\begin{array}{c}0 \\
(0.0 \%)\end{array}$ & $\begin{array}{c}0 \\
(0.0 \%)\end{array}$ \\
\hline \multirow[b]{2}{*}{$\begin{array}{l}\text { Knowledge } \\
\text { Scoring Category } \\
\text { Percentage (\%) }\end{array}$} & \multicolumn{3}{|c|}{ After Training/Briefing } \\
\hline & $\begin{array}{l}\text { Study } \\
\text { Group } \\
(n=30)\end{array}$ & $\begin{array}{l}\text { Control } \\
\text { Group } \\
(n=30)\end{array}$ & $\begin{array}{l}\text { Total } \\
(n=60)\end{array}$ \\
\hline $\begin{array}{l}\text { Very poor } \\
(0-19 \%)\end{array}$ & $\begin{array}{c}0 \\
(0.0 \%)\end{array}$ & $\begin{array}{c}1 \\
(3.3 \%)\end{array}$ & $\begin{array}{c}1 \\
(1.7 \%)\end{array}$ \\
\hline $\begin{array}{l}\text { Poor } \\
(20-39 \%)\end{array}$ & $\begin{array}{c}0 \\
(0.0 \%)\end{array}$ & $\begin{array}{c}2 \\
(6.7 \%)\end{array}$ & $\begin{array}{c}2 \\
(3.3 \%)\end{array}$ \\
\hline $\begin{array}{l}\text { Fair } \\
(40-59 \%)\end{array}$ & $\begin{array}{c}6 \\
(20.0 \%)\end{array}$ & $\begin{array}{c}15 \\
(50.0 \%)\end{array}$ & $\begin{array}{c}21 \\
(35.0 \%)\end{array}$ \\
\hline $\begin{array}{l}\text { Good } \\
(60-79 \%)\end{array}$ & $\begin{array}{c}14 \\
(50.0 \%)\end{array}$ & $\begin{array}{c}12 \\
(40.0 \%)\end{array}$ & $\begin{array}{c}26 \\
(45.0 \%)\end{array}$ \\
\hline $\begin{array}{l}\text { Excellent } \\
(80-100 \%)\end{array}$ & $\begin{array}{c}10 \\
(30.0 \%)\end{array}$ & $\begin{array}{c}0 \\
(0.0 \%)\end{array}$ & $\begin{array}{c}10 \\
(15.0 \%)\end{array}$ \\
\hline
\end{tabular}


The results of the re-test showed that there was an increase in the knowledge level of pre-school teachers on vision screening in the Study Group compared to the Control Group after the training/briefing. All pre-school teachers from the Study Group obtained score of at least $40 \%$ and above, which falls between the score category of fair to excellent. About half of the pre-school teachers in the Study Group obtained a good score (60-79\%) while one third were in the excellent category and only $20 \%$ obtained only a fair score (40-59\%). For the Control Group, 50\% of the pre-school teachers were in the fair category, while $40 \%$ were in the good category followed by poor category with $6.67 \%$ and the very poor category managed a score of $3.33 \%$. None of the teachers from the Control Group managed to score in the category $80 \%$ or more. Teachers in the Study Group had a significantly higher post-training test results $(73.24 \pm 11.73 \%)$ compared to those in the Control Group (56.22 $\pm 13.11 \%)(p=0.027)$. There was a significant improvement in the mean overall test results after the training in the Study Group compared to the Control Group (Table 4) $(p<0.001)$.

Table 4: Comparison of theory test results before and after training in the study and control groups

\begin{tabular}{llcc}
\hline & & \multicolumn{2}{c}{ Pre-school Teacher } \\
\cline { 3 - 4 } & & $\begin{array}{c}\text { Study Group } \\
(\mathbf{n = 3 0 )}\end{array}$ & $\begin{array}{c}\text { Control } \\
\text { Group } \\
(\mathbf{n = 3 0 )}\end{array}$ \\
\hline \multirow{3}{*}{ Theory } & Before Training & $51.31 \pm$ & $57.47 \pm$ \\
Test & Mean \pm SD & 12.74 & 9.67 \\
Results & Mean \pm SD & $73.24 \pm$ & $56.22 \pm$ \\
Score & Mean & 11.73 & 13.11 \\
$(\%)$ & Difference & $21.93 \pm$ & $1.24 \pm$ \\
& Mean \pm SD & 15.48 & 14.24 \\
& Paired-t test & $\mathrm{p}<0.001$ & $\mathrm{p}=0.636$ \\
\hline
\end{tabular}

The relationship between age and knowledge level was determined using Spearman Correlation in view of the fact that the data was found not to be normally distributed for the age, number of years working in pre-schools and level of knowledge of pre-school teachers according to the Shapiro-Wilk test. Analysis showed that there was a nonsignificant relationship between the age and knowledge level of preschool teachers $(r=-0.22, p>0.05)$. There was also no significant relationship between the number of years working in pre-schools and the level of knowledge of the screener $(r=-0.07)(p>0.05)$.

\section{Discussion}

The results showed that majority (55\%) of the pre-school teachers involved in this study had a fair level of knowledge on pre-school vision screening before they were given any training/briefing. It was apparent that a large number of the pre-school teachers had little knowledge about vision impairment and vision screening, as evidence by the observation that approximately $33 \%$ of the participants displayed poor level of knowledge, and only $8.3 \%$ of them had scores that fall within the good category. This may be due to limited resources about vision impairment and vision screening provided in the curriculum of pre-school teachers in Malaysia. In addition, many teachers involved in this study have never experienced any visual impairment, as it was noted that only a few of them wore glasses to correct refractive errors. This may have led to reduced awareness about vision impairment and its impact on the daily life of the school children. This low level of awareness may have led to the teachers making less effort to seek information through reading materials or electronic media on visual impairments. Therefore, there is a need to improve the level of knowledge of pre-school teachers through proper training and education. Knowledge on visual impairments among pre-school children and vision screening would also need to be added to the training curriculum of preschool teacher ideally through the provision of a specific teaching module on vision impairments and the effects on schoolchildren and their ability to learn.

The fair knowledge possessed by the pre-school teachers on vision impairment and vision screening of pre-school children as demonstrated in this study could influence the effectiveness of pre-school vision screening tests performed by the teachers as suggested by Marsh-Tootle et al. (16). In order to obtain reliable screening test results, the level of knowledge of preschool teachers on vision impairment and vision screening needs to be improved. This can be done by providing adequate vision screening training or courses to them as suggested by the previous studies (1718). Thus, baseline information about the knowledge level of pre-school teachers before they undergo training or briefing is important so as to be able to assess the impact of the training given. To our knowledge, no findings have been published about the level of knowledge of pre-school teachers on vision impairment and vision screening for pre-school children before training is given.

Based on the analysis of this study, pre-school teachers displayed a higher score in the first category of questions, namely the preparation or pre-school vision screening tests. High scores obtained in Q1 and Q2 indicated that teachers were aware of the importance of vision screening and its role in early detection of vision impairment among pre-school children. In addition, they also knew about the tests involved in vision screening, as reflected by a relatively high scores for Q3. However, the lowest score obtained in this category was related to knowledge on the equipment used for pre-school vision screening (Q4). This was expected since the pre-school teachers have never been introduced to the equipment used for vision screening tests. The highest score obtained in this category was Q5, which assesses knowledge on the method to take care of the screening equipment. This reflects the logic and sense of responsibility of the pre-school teachers in managing vision screening tools. 
As anticipated, teachers in both groups scored lower in the second category, i.e. the conduct of pre-school vision screening tests. This is most likely because the pre-school teachers have never been introduced to screening tests and their procedures prior to their participation in this study. The lowest number of correct answers for this category was on the topic related to visual acuity (VA) test (Q12). Although teachers may have been introduced to the VA test while undergoing eye examinations themselves at either hospitals or optometric practices before, they may not have been exposed to the normal values used in the VA test. The second question which showed a low score was related to the Hirschberg test. This is most likely because the Hirschberg test is usually only performed by eye care practitioners to detect the presence of strabismus. Thus it would not have been an easy question that could be answered deductively. Based on these findings, it is concluded that pre-school teachers had a low level of knowledge about the Hirschberg test and the normal values for the VA test. Therefore, these topics should be emphasized more during the vision screening training so that the quality of screening and subsequent referral can be further enhanced.

The results of the correlation analysis showed no significant relationship between the age and duration of working experience in pre-schools with the teacher's level of knowledge on pre-schools vision screening. This indicates that age, and teaching experience are not factors that contribute to the level of knowledge of pre-school teachers on vision screening. Although a large number of pre-school teachers were over 40 years old and had more than ten years of teaching experience, they had only a fair level of knowledge on vision impairments and vision screening. It is plausible that they may be exposed to limited information on the development of children's eyes and vision. There may also be a lack of information on vision care services incorporated into the pre-school teacher's training curriculum. Hence, a well-structured, relevant and current teaching module which includes knowledge on vision impairment and step-by-step procedures on how to conduct vision screening would help teachers to conduct screening tests on pre-school children more effectively.

Previous studies have suggested that the validity of these screening tests, which include the values of sensitivity, specificity, positive predictive value (PPV) and negative predictive value (NPV) of the findings by pre-school and school teachers can determine the effectiveness of vision screening training given to them $(3,6,13,18-22)$. Nevertheless, these values do not indicate the teachers' actual understanding of the screening test, but instead, only indicates their ability to perform the screening tests and the validity of the test results they obtained. A comparison of the level of knowledge of teachers before and after the training is given to illustrate the teachers' understanding of the vision screening tests. The results of the theory test of pre-school teachers Study Group found that there was an increase in score of $42.74 \%$ after receiving theoretical and practical training. This indicates that effective vision screening training is essential in improving the understanding of preschool teachers on the purpose, importance and method of conducting screening tests on preschool children. On the other hand, the results of the theory test of the pre-school teachers in the Control Group indicate no significant effect of the conventional briefing method in improving their knowledge on vision screening of the preschoolers.

The effectiveness of the training provided and the competence of the teachers in performing the vision screening tests as well as their ability to correctly refer children with visual problems for a more complete assessment provides another method in which the visual health of children, especially pre-school children, can be optimized. This study shows a method by which vision screening of pre-school children can be done competently without increasing the demand on conventional School Health Teams, who are already engaged with children aged 7-12 years. The existence of ability of pre-school teachers to provide quality referrals with a low false positive rate means that referrals to existing healthcare services can be optimized, as most of these referrals would be of actual cases needing intervention. Since visual problems such as amblyopia, strabismus and refractive errors are the common issues among pre-school children, these children would then be able to undergo treatment. This would improve their ability to see well, and thus be better suited to cope with their learning activities and social interactions. This study demonstrates a viable means of increasing the nation's ability to help screen pre-school children using existing human resources without needing to tap into or impose an additional burden on public health systems. The training of pre-school teachers is already on-going and the addition of 4-8 hours to their training curriculum is possible. This has been discussed informally with state KEMAS management, who is very supportive of this initiative, provided it is implemented at the federal level.

\section{Conclusions}

This vision screening training module was effective in improving the knowledge of pre-school teachers in vision screening of pre-school children. Proper training on vision screening includes teaching the importance of vision screening, vision impairments seen among children and their impact on children's lives as well as the step-by-step procedures to carry out vision screening tests on pre-school children. All these components are essential. As the level of knowledge of vision screeners, such as pre-school teachers, on children's vision impairments and vision screening techniques improves, the effectiveness of their vision screening ability is thus assured. Hence, more lay screeners can be trained to conduct pre-school vision screening with reliable outcomes. When vision impairments of children are detected at an early stage, immediate referral and early treatment yields a better prognosis and minimizes the impact of vision impairment on an individual's physical, mental and psychological well-being. 


\section{Acknowledgement}

This work was supported by the Industry and Community Partnership Affair (HEJIM) Community research grant UKMHEJIM022010. The authors wish to thank the Federal Territory and Selangor Community Development Department (KEMAS) of the Ministry of Rural and Regional Development, all the pre-school teachers, pre-school children and parents who participated in this study.

\section{References}

1. Duratul Ain H, Omar R, Knight VF. Profile of visual impairment among preschool children. Jurnal Sains Kesihatan Malaysia. 2009;7(1):25-36.

2. Kong L, Fry M, Al-Samarraie M, Gilbert C, Steinkuller PG. An update on progress and the changing epidemiology of causes of childhood blindness worldwide. J AAPOS. 2012;16(6):501-7.

3. Korani, J, WilliamsJD, Rose A \& Khanna R. A Prospective Study to Assess the Quality of Preliminary Eye Screening Done on School Children by Teachers in Andhra Pradesh. J Comm Med Health Educ. 2015;5(2):342.

4. Latorre-Arteaga S, Gil-González D, Bascarán C, Núñez RH, Morales MD \& Orihuela GC. Visual health screening by schoolteachers in remote communities of Peru: implementation research. Bull World Health Organ. 2016;94: 652-9.

5. Saxena R, Vashist P, Tandon R, Pandey RM, Bhardawaj A \& Menon V. Accuracy of Visual Assessment by School Teachers in School Eye Screening Program in Delhi. Indian J Community Med. 2015;40(1):38-42.

6. Kaur G, Koshy J, Thomas S, Kapoor H, Zachariah JG \& Bedi S. Vision Screening of School Children by Teachers as a Community Based Strategy to Address the Challenges of Childhood Blindness. J Clin Diagn Res. 2016;10(4): NC09-14.

7. Limitations of vision screening programs. American Optometric Association. 2019. Available from: https:// www.aoa.org/patients-and-public/caring-for-yourvision/comprehensive-eye-and-vision-examination/ limitations-of-vision-screening-programs

8. Juggernath YM \& Knight SE. Knowledge and practices of visual acuity screening by primary school educators. Afr Vis Eye Health. 2015;74(1): 309-13.

9. Lianov $L$ \& Johnson M. Physician competencies for prescribing lifestyle medicine. JAMA. 2010;304:2023.

10. Birkhead AG, Foote S, Monlezun DJ, Loyd J, Joo E, Leong B, Sarris L \& Harian TS. Medical student-led community cooking classes: a novel preventive medicine model that's easy to swallow. Am J Prev Med. 2014;46:e41-42.

11. Omar R, Knight VF, Ahmad Zahidi AA, Mohd Saat NZ, Tan XL. Effectiveness of vision screening program conducted by pre-school teachers. Malaysian Journal of Public Health Medicine, 2018; Special Volume(1): 41-50.
12. Snedecor GW, Cochran WG. Statistical methods, $8^{\text {th }}$ ed. Ames: lowa State Press;1989.

13. Vision in Preschoolers (VIP) Study Group. Findings from the Vision in Preschoolers (VIP) Study. Optom Vis Sci. 2005;86:619-23.

14. Duratul Ain H. Preschool Vision Screening Model And Early Optometric Intervention Among Children Master Thesis. 2009. Optom Vis Sci., Faculty of Health Sciences, Universiti Kebangsaan Malaysia.

15. Omar R, Knight VF, Asma Ahida AZ, Nur Zakiah MS and Tan XL. 2018 Effectiveness Of Vision Screening Program Conducted By Pre-School Teachers. Malaysian Journal of Public Health Medicine, Special Volume (1): 41-50

16. Marsh-Tootle WL, Funkhouser E, Frazier MG, Crenshaw K \& Wall TC. Knowledge, attitudes, and environment: What primary care providers say about pre-school vision screening. Optom Vis Sci. 2010;87:104-11.

17. Pattison B \& Plymat K. Vision screening of school children: Should it be continued? Contemp Nurse. 2001;10:63-171.

18. Krumholtz I. Educating the educators: increasing grade-school teachers' ability to detect vision problems. Optometry. 2004;75:445-51.

19. Tung IC, Tsai RK., Cheng CH \& Shew MM. Comparison of trained kindergarten teachers and public health nurses in the administration of preschool amblyopia and strabismus screening tests. Tzu Chi Med J. 2006;18:29-33.

20. Sharma A, Li L, Song Y, Choi K, Lam DS, Zhang M, Zheng M, Zhou Z, Liu X, Wu B \& Congdon N. Strategies to improve the accuracy of vision measurement by teachers in rural Chinese secondary schoolchildren. Xichang Pediatric Refractive Error Study (X-PRES) Report No. 6. Arch Ophthalmol. 2008;126(10):143440.

21. Sudhan A, Pandey A, Pandey S, Srivastava P, Pandey $K P$ \& Jain BK. Effectiveness of using teachers to screen eyes of school-going children in Satna district of Madhya Pradesh, India. Indian J Ophthalmol. 2009;57:455-58.

22. Sabri K, Thornley P, Waltho D, Warren T, Laverty L, Husain S, Farrokhyar F \& Higgins D. Assessing accuracy of non-eye care professionals as trainee vision screeners for children. Can J Ophthalmol. 2016;51(1):25-9. 